\title{
Nurses' knowledge and practice regarding Wound Infection in Surgery Unit at Assuit University Children Hospital
}

\author{
Hanan A. Abd Elhay, Mohamed A. Osman, Fathia Z. Mohammed \& Salwa A. Marzouk \\ Demonstrator at Pediatric Nursing Department, Faculty of Nursing, Assuit University, Egypt. \\ Professor of Pediatric Surgery, Pedtric Nursing, Faculty of Nursing, Assuit University, Egypt. \\ Assistant Professor of Pediatric Nursing, Faculty of Nursing, Assuit University, Egypt.
}

\begin{abstract}
Surgical site infections (SSIs) are one of the most important healthcare-associated infections. The SSIs play a major role in increasing morbidity and mortality rates, prolonging hospitalization, and increasing hospital readmissions. The aim of the study was to assess nurses' knowledge and practice regarding wound infection in surgery unit at Assuit University Children s' Hospital. A descriptive research design was used in this study. Subjects and Methods: the study was carried in surgery unit of Assuit University Children Hospital. A convenience sample of 30 nurses working in surgery unit of Assuit University Children Hospital. Data collection tools were a structured questionnaire interview sheet to assess nurses' knowledge and an observation checklist to evaluate nurses' practice regarding wound infection. Results were shown satisfactory level of knowledge and unsatisfactory level of practice regarding wound infection in surgery unit at Assuit University Children Hospital. The study concluded that nurses had satisfactory level of knowledge and deficiency in practice. Statistically significant relations were shown between knowledge and practices among studied nurses. The study recommended Provision of continuing education programs associated with clinical training related to infection control
\end{abstract}

Keywords: Wound Infection/Surgical Site Infection, Nurses, Pediatric/Children, Knowledge\& Practice.

\section{Introduction}

Surgical site infection (SSI) is one of the most important healthcare-associated infections (HAIs). The SSIs account for up to $25 \%$ of HAIs. It is estimated that $40 \%$ to $60 \%$ of SSIs are preventable. The SSIs may prolong hospital stay from 6-30 days, increase antimicrobial and laboratory costs, and require added health care interventions (Scott, 2009). The SSI is an infection that develops within 30 days after a surgical procedure or within 1year if an implant was placed and infection appears to be related to the surgery (Aderson et al., 2007). The SSI can be superficial, involving only skin, or may be more serious involving subcutaneous tissue, organs, or implanted material (CDC, 2010).

The development of an SSI depends on contamination of the wound site at the end of a surgical procedure and specifically relates to the pathogenicity and inoculum of microorganisms present, balanced against the host immune response. The microorganisms that cause SSI are usually derived from the patient (endogenous infection), being present on their skin or form an opened viscus. Exogenous infection occurs when microorganisms from instruments or the theatre environment contaminate the site at operation, when microorganisms from the environment contaminate a traumatic wound, or when microorganisms gain access to the wound after surgery. Practices to prevent SSI are therefore aimed at minimizing the number of microorganisms introduced into the operative site (Health Protection Agency, 2006).

The risk of SSI is increased by factors that increase the risk of endogenous contamination as procedures that involve parts of the body with a high concentration of normal flora such as the bowel, increase the risk of exogenous contamination as prolonged operations that increase the length of time that tissues are exposed, and diminish the efficacy of the general immune response (for example, diabetes, malnutrition, or immunosuppressive therapy with radiotherapy ,chemotherapy or steroids) or local immune response (for example, foreign bodies, damaged tissue or formation of a hematoma) (Niemeyer et al., 2007).

Signs and symptoms of SSI including purulent discharge from the surgical site, delayed healing not previously anticipated, redness (erythema or cellulitis) around the wound, abnormal smell coming from wound site, friable, bleeding granulation tissue despite appropriate care and management, Lymphangitis, Presence of at least one of the signs and symptoms of infection such as pain or tenderness, localized swelling, redness, and heat (Vanessa, 2009).

The role of the nurse is summarized as follows: prevention that focuses on assessing the child risk for infection from invasive procedures and therapies. Health promotion and maintenance activities included monitoring vital signs for alteration in 
temperature and other parameters, administering prescribed antibiotics and evaluating the patient response to therapy, as well as implementing and maintain aseptic techniques and infection control measures such as universal precautions. They also involve encouraging a balance of rest and activity, good nutritional intake and other general health measures to support immunological functions and healing (Patricia et al., 2009).

Prevention of SSI includes preoperative hair removal only be removed when necessary. If removed, the hair should be clipped immediately before the procedure. Glycemic control, hand and forearm preparation, and antimicrobial prophylaxis. The area around the incision site should be thoroughly cleaned to remove gross contamination and an appropriate antiseptic agent should be used (Jan \& Forren, 2015).The Association of perioperative Registered Nurses (AORN) recommended practice for environmental cleaning states that patients should be provided with a clean environment and that a safe, clean environment should be reestablished after each surgical procedure. According to (AORN), contact precautions should be used when perioperative staff is caring for patients who have a known or suspected infection or are colonized with microorganisms transmitted by direct or indirect contact (AORN, 2014).

\section{Significance of the study}

While advances have been made in infection control practices, application of infection control and proper use of antiseptic techniques followed in Pediatric Surgical Unit, postoperative infection is still the first priority to be avoided as it is a life threating condition. Wound infection will increase morbidity, inpatient stay, hospital cost and mortality of pediatric surgical patients, which makes the health team do great efforts to decrease the incidence and risk of surgical site infection. Nurse is an important member of health team who should have knowledge, good attitude and being skillful in application of infection control techniques in wound dressing, so this study was carried out to assess and evaluate their knowledge and practice regarding application of the universal precautions that use to decrease the incidence of wound infection occurrence.

\section{Aim of the study}

The aim of this study was to assess the nurses' knowledge and practice regarding wound infection in Surgery Unit at Assuit University Children's Hospital

\section{Subjects \& methods \\ Design}

A descriptive research design was used in this study. Setting

The study was conducted in surgery Unit at Assuit University Children's Hospital.

Sample

A convenience sample of (30) nurses who are working in the Surgery Unit at Assuit University Children Hospital. (16) nurses from the inpatient department and (14) nurses from the operating room.

\section{Tools of the study}

Two tools were used in this study:

Tool I: A structured interview questionnaire

It was developed by the researcher after reviewing related literature to assess nurse's knowledge and it included two parts:

Part (I): Personal characteristics of the studied nurses such as age, qualifications, years of experience and attending training courses about infection control.

Part (II): Questions to assess nurse's knowledge regarding wound infection as definition of infection, definition of surgical site infection, causes, and risk factors, signs and symptoms and nursing care pre, during and post-operative.

\section{Tool II: Observation checklist}

It was adopted from (Elizabeth et al., 2006) to evaluate nurses' practice regarding the application of infection control measures in the pediatric surgical unit. It included (45) steps, hand washing (14 steps), gloving technique (10 steps) and dressing technique (21 steps).

\section{Method}

- An official approval letter was obtained from the dean of the faculty of nursing, Assuit University to the director of Pediatric surgery unit at Assuit University Children's Hospital.

- An oral consent was taken from all nurses who participated in the study.

- Content validity and reliability; it was established for the two tools by a panel of five experts from both surgical and pediatric nursing staff.

\section{A Pilot study}

It was carried out on 10\% (3 nurses) to test clarity of the questionnaire, estimate the length of time needed to collect data and modifications were done and they were included in the study

\section{Field of the work}

This study was carried out through a period of three months from November (2014) to February (2015). It included nurses every other day working at surgery unit; indirect observation for infection control measures was done for each nurse. The time for observation ranged from 1-2 hours. Only one nurse observed per day. Interviewing of studied nurses was 
conducted according to their available time to collect data; two nurses were interviewed per day. The time needed for each interview ranged from 20-25 minutes according to the response of the participant nurses.

\section{Ethical considerations}

Oral consent was taken from all nurses who participated. Every nurse was reassured that information which obtained would be confidential and used only for the purpose of the study sample.

\section{Scoring system}

Knowledge score of two grades was given for correct complete answer, one grade when nurses given incomplete correct answer and zero grade for incorrect answer. Total score of knowledge was summed and classified to:

Unsatisfactory $<60 \%$ and Satisfactory $\geq 60 \%$

Practice score of two was given for correct complete answer, zero grade when nurses given correct incomplete answer and zero grade for incorrect answer. Total score of practice was summed and classified to:

Poor $<60 \%$, Satisfactory $60-80 \%$ and Good $\geq 80 \%$

Data analysis

Data entry and data analysis were done by using SPSS program (Statistical Package for Social Science) version 16. Data were presented as number, percentage, mean and standard deviation. Chi- square test and fisher exact test were used to compare qualitative data. Pearson correlation was used to measure correlation between score of knowledge and practice. $\mathrm{P}$ value considered statistically significant when $\mathrm{p}<0.05$.

\section{Results}

Table (1): Distribution of the studied nurses according to their personal characteristics

\begin{tabular}{|c|c|c|}
\hline Item & No. $(n=30)$ & $\%$ \\
\hline \multicolumn{3}{|l|}{ Age } \\
\hline$<25$ years & 10 & 33.3 \\
\hline $25-30$ years & 16 & 53.3 \\
\hline$>30$ years & 4 & 13.3 \\
\hline Mean \pm SD (Range) & \multicolumn{2}{|c|}{$26.90 \pm 5.78(21.0-45.0)$} \\
\hline \multicolumn{3}{|l|}{ Qualifications } \\
\hline Graduate from the School of Nursing & 15 & 50.0 \\
\hline Health Technical Institute Alumna & 12 & 40.0 \\
\hline Graduate from Faculty of Nursing & 3 & 10.0 \\
\hline \multicolumn{3}{|l|}{ Years of experience } \\
\hline$<5$ years & 8 & 26.7 \\
\hline $5-<10$ years & 12 & 40.0 \\
\hline$\geq 10$ years & 10 & 33.3 \\
\hline Mean \pm SD (Range) & \multicolumn{2}{|c|}{$8.23 \pm 5.18(1.0-23.0)$} \\
\hline \multicolumn{3}{|c|}{ Attending training courses about infection control } \\
\hline Yes & 25 & 83.3 \\
\hline No & 5 & 16.7 \\
\hline \multicolumn{3}{|l|}{ Duration of course } \\
\hline$<3$ days & 6 & 24.0 \\
\hline 3 - 6 days & 18 & 72.0 \\
\hline$>6$ days & 1 & 4.0 \\
\hline
\end{tabular}


Table (2): Nurses' knowledge regarding nursing care to prevent wound infection.

\begin{tabular}{|l|c|c|}
\hline \multicolumn{1}{|c|}{ Items } & \multicolumn{2}{c|}{ No. $(\mathbf{n}=\mathbf{3 0})$} \\
\hline Before operation & \multicolumn{2}{|c|}{$\%$} \\
\hline Complete correct & 18 & 60.0 \\
\hline Incomplete correct & 12 & 40.0 \\
\hline During operation & 18 & 60.0 \\
\hline Complete correct & 12 & 40.0 \\
\hline Incomplete correct & \multicolumn{2}{|c|}{} \\
\hline After operation & 28 & 93.3 \\
\hline Complete correct & 2 & 6.7 \\
\hline Incomplete correct & \multicolumn{2}{|c|}{} \\
\hline
\end{tabular}

(^) More than one practice was done

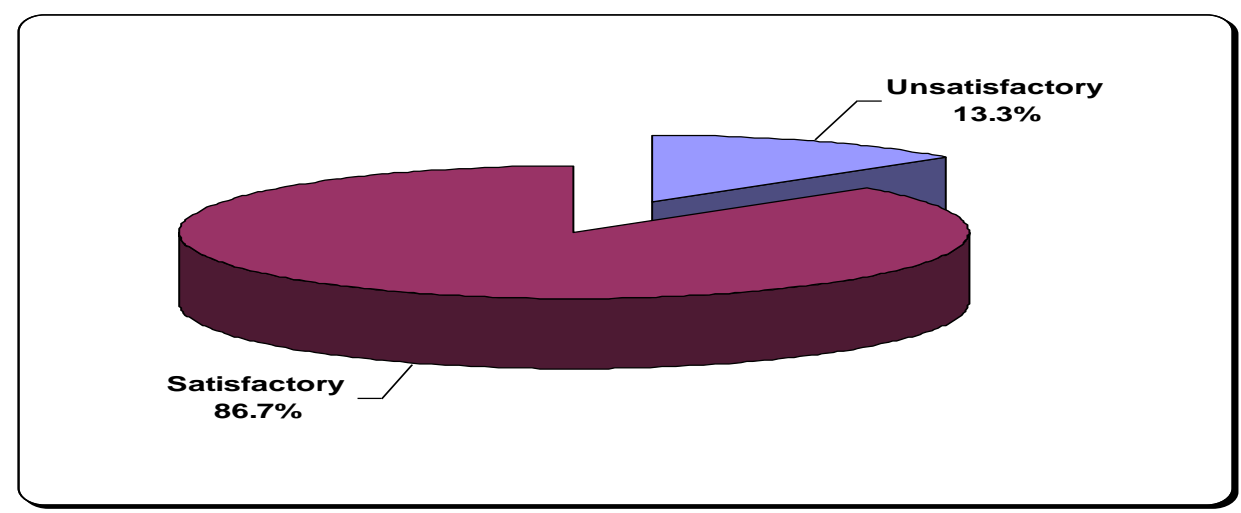

Figure (1): Total score of the studied nurses' knowledge about wound infection

Table (3): Total Scores of the studied nurses practices related to prevention of wound infection.

\begin{tabular}{|l|c|c|}
\hline \multicolumn{1}{|c|}{ Items } & \multicolumn{2}{c|}{ No. $(\mathbf{n}=\mathbf{3 0})$} \\
\hline Hand washing & \multicolumn{2}{|c|}{$\%$} \\
\hline Satisfactory $60-<80 \%$ & \multicolumn{2}{|c|}{} \\
\hline Good $\geq 80 \%$ & 22 & 26.7 \\
\hline Gloving technique & 2 & 63.3 \\
\hline Satisfactory $60-<80 \%$ & 28 & 93.3 \\
\hline Good $\geq 80 \%$ & \multicolumn{2}{|}{} \\
\hline Dressing technique & 9 & 30.0 \\
\hline Poor $<60 \%$ & 18 & 60.0 \\
\hline Satisfactory $60-<80 \%$ & 3 & 10.0 \\
\hline Good $\geq 80 \%$ & \multicolumn{2}{|c|}{} \\
\hline
\end{tabular}

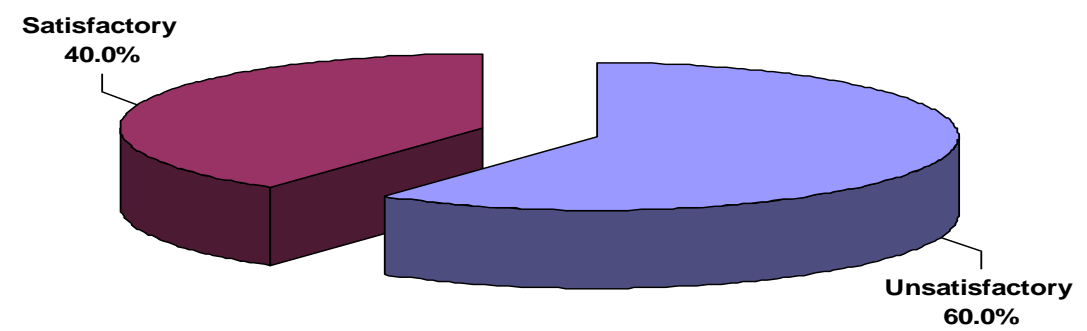

Figure (2): Total score of the studied nurses practices 
Table (1): Showed the personal characteristics of the studied nurses, it was found that more than half $(53.3 \%)$ of the studied nurses their ages ranged from 25 years to less than 30 years, $(33.3 \%)$ of them were under 25 years old and $(13.3 \%)$ of them were more 30 years old with mean age + SD26.90+5.75. Regarding to qualifications, one-half of studied nurses $(50 \%)$ had diplom of School of Nursing, (40\%) had Health Technical Institute and (10\%) had graduated from faculty of Nursing. According to the years of experience it was noticed that less than half $(40 \%)$ of the studied nurses had experience from 5 years to < 10 years, $(33.3 \%)$ had experience more than 10 years and $(26.7 \%)$ had experience less than 5 years. As regarding attending training courses, more than three quarters $(83.3 \%)$ of studied nurses had training courses while $(16.7 \%)$ not had. $(72 \%)$ of them had training courses of 3 days and $(68 \%)$ of these courses were held out of hospital.

Table (2): Regarding nurses' knowledge about nursing care to prevent wound infection table (2) showed that more than half $(60.0 \%)$ of the studied nurses knew how to care the child before and during the operation completely correct and the majority of them (93.3\%) had complete correct answer about care after operation.

Table (3): Regarding total Scores of the studied nurses practices table (3) showed that $(26.7 \%)$ of nurses had satisfactory hand washing practice and (73.3\%) of them was good. According to gloving technique, the majority of them $(93.3 \%)$ had good level of practice. In dressing technique $(30.0 \%)$ of nurses had poor level of practice while more than half of them $(60.0 \%)$ had satisfactory level, only $(10.0 \%)$ of nurses had good level.

Figure (1): Represented total score of the studied of nurses' knowledge about wound infection, it found that the majority $(86.7 \%)$ of studied nurses had satisfactory level of knowledge while (13.3\%) had unsatisfactory level.

Figure (2): Demonstrated total score of studied of nurses' practice about wound infection, it was found that three-fifths of studied nurses had unsatisfactory level of practice while two fifths had satisfactory level.

\section{Discussion}

SSIs have been shown to account for up to $16 \%$ of all HCAIs. SSI can often be prevented with appropriate care before, during and after surgery. Patients with surgical site infections (SSIs) are 5 times more likely to be readmitted to the hospital, $60 \%$ more likely to be admitted to the intensive care unit (ICU), twice as likely to die, and are hospitalized 7 days longer on average than patients in whom SSIs do not develop. Therefore, SSIs may severely affect financial reimbursement. A postoperative complication, such as infection, increased cost of care by over $54 \%$ with a resulting profit margin decreased to $3.4 \%$ (Health Protection Agency, 2012). The aim of this study was to assess the nurses' knowledge and practice regarding wound infection in Surgery Unit at Assuit University Children s' Hospital.

Results of the present study revealed that more than half $(53.3 \%)$ of the studied nurses were in the age group from 25 to less than 30 years old and half of them graduated from the nursing school, these results were agree with Kabir, (2010) \& Gamal, (2005) while disagree with Abd-Al Rahman, (2015) \& Khalifa, (2011) who stated that more than half of nurses were less than twenty-five years old. As regard years of experience, it was noticed that less than half $(40.0 \%)$ of nurses had experience from 5 to less than 10 years. This result agree with Kabir, (2010) who found that less than half $(40.0 \%)$ of nurses had experience from 5 to less than 10 years and disagree with Abd-Al Rahman, (2015) and Khalifa, (2011) who reported that more than half of the studied nurses had experience from 5 to less than 10 years.

Results of the present study showed that about the majority of the studied nurses $(83.3 \%)$ attended training courses about infection control, This result agree with Abd-Al Rahman, (2015) who reported that more than half of studied nurses had attended training programs while disagree with Khalifa, (2011) who stated that less than half of nurses had not attended training courses .

As regard total score of nurses, knowledge about wound infection, it was noticed that majority (86.7) of nurses had satisfactory level of knowledge related to wound infection and perioperative care. These results agree with Ali, (2011) who demonstrated that the studied nurses were better in their total percent score of knowledge than other health team members and with Abd-Al Rahman, (2015) who revealed that majority of nurses had high scores of knowledge. Also, agree with Labrague et al., (2012) who referred that more than half of nurses of the respondents (excellent) while (38.09\%) scored very good. On the contrary and disagree with Soliman, (2007) who demonstrated that most of nurses in general showed poor knowledge level. In addition, Abolwafa, (2009) and Ebrahem (2009) found that before the training program, nurses had poor knowledge and practice and this was indicated by their low scores. Also, it disagrees with Kabir, (2010) who reported that nurses had low level of knowledge about wound infection.

Regarding nurses, practice of hand washing, it was noticed that less than three quarters $(73.3 \%)$ of the 
studied nurses had good level of practice, more than one-quarter $(26.7 \%)$ of them had satisfactory level of hand washing practice. This supported by Ali, (2011) who stated that the majority of nurses followed the proper hand washing technique in her performance. Conversely, El shenawi, (2002) stated that the mean percentage of the nurses performance regarding to hand washing was poor.

Results of the current study showed that the majority of studied nurses had good level of practice regarding gloving technique. These finding were in accordance with Ali, (2010) who revealed that the superiority of nurses than other health team members in knowledge and performance of personnel protective equipment. On contrary, El shenawi, (2002) cited that the performance of the majority of nurses regarding using gloves was poor. As regard nurses, practice of dressing technique, only $(10.0 \%)$ of nurses had good level of practice of dressing technique. Dressing care may vary according to the surgeon's preference and agency or institutional policy. As there are different types of wounds, there are different approaches to wound care. It is important for nurses practicing in the profession to follow agency guidelines, observe the preferences of the physician or qualified practitioner, and to review recent research and published information on the optimal care for the type of wound being treated (Association of Surgical Technologists, 2012)

Regard the total score of the studied nurses' practices the current study showed that more than half $(60.0 \%)$ of the studied nurses had unsatisfactory level of practice. These findings indicated that nurses need to improve their practices regarding standard /universal precautions and dressing technique with activating the role of infection control team to monitor and correct performance of nurses. These agree with Abd El Hafez (2007) who demonstrated that generally had poor level of practice. On the same line Soliman, (2007) stated that nurses had unsatisfactory level of practice regarding standard precautions. Ebrahem, (2009) mentioned that nurses had unsatisfactory level of performance regarding standard precautions and disagree with Kabir, (2010) who reported that nurses had high level of practice regarding standard precautions to prevent surgical site infection. Also, this study disagrees with Ali, (2010) \& Gamal, (2005) who nurses had good level of practice regarding standard precautions.

\section{Conclusion}

Based on the results of the present study, it can be concluded that

Nurses had satisfactory level of knowledge and unsatisfactory level of practice regarding wound infection.

\section{Recommendations}

Based on the results of the present study it can be recommended that

- Provision of continuing education programs associated with clinical training

- Surveillance system should be established to identify risk factors and rates of wound infection in children to be a feedback for further studies which will help to decrease wound infection.

- Provision of adequate resources and facilities, (such as protective barriers, sinks, soap, towels) and other equipment.

\section{References}

1. Abdel Hafez K., (2007): Compliance with Universal Infection Control Precautions among Health Care Personnel in Critical Care Units, Unpublished Master Thesis in Critical Care Nursing, Faculty of Nursing Assuit university, 95-104.

2. Abdel Rahman S., (2015): Assessment of Nurses' Knowledge, and Practice regarding Infection Control in Operating Room at main Assuit University and Al Eman Hospital. Un published Thesis in adults Nursing, Faculty of Nursing, Assuit university, 82-90

3. Abolwafa N., (2009): Assessment of Nurses Knowledge and Practice related to Infection Control in the Neonatal Units at El - Minia City Hospitals, Thesis in Pediatric Nursing, Faculty, Assuit University, 40-105.

4. Association of perioperative Registered Nurses (2014): Recommended practices for prevention of transmissible infections in the perioperative practice setting. In: Perioperative Standards and Recommended Practices. Denver, CO: (AORN) Inc.; 2014:385-417.

5. Aderson D., Sexton D., Kanafani Z., Auten G., \& Kaye K., (2007): Severe Surgical Site Infection in Community Hospitals: Epidemiology, Key procedures, and the changing prevalence of methicillin-resistant Staphylococcus aureus. Infect Control Hosp Epidemiol. 28(9):1047-1053.

6. Ali A., (2011): Knowledge and Practice of Health Team about Infection Control in the Neonate Intensive Care Units at Assuit El- Minia University Hospital Un published Doctorate Thesis in Premature and Pediatric Nursing, Faculty of Nursing, Assuit university, 131-140

7. Association of Surgical Technologists (2012): Surgical Technology for the Surgical Technologist: A positive Care approach. $4^{\text {th }}$ ed, 
Chapter 12, surgical care management, approach, Cengage Learning, USA. Pp. 329- 82

8. Center for Disease Control \& Prevention (CDC) (2010): Data from the National Hospital Discharge Survey

9. Ebrahem G., (2009): Nurses Application of Infection Control Precautions in Hemodialysis Unit at El- Mansoura University Children Hospital. Unpublished Master in Pediatric Nursing, Faculty Nursing University of Alexandria, 60-109

10. El Shenawi S., (2002): Establishing Standards for Prevention and Control of Nosocomial Infection in the intensive Care Units at the Alexandria Main University Hospital. Faculty of Nursing, Alexandria University, 35-95.

11. Gamal L., (2005): Establishing standard for prevention of Nosocomial infection in the recovery rooms and surgical ward at Elminia University Hospital. Unpublished doctoral thesis. Faculty of Nursing, Assiut University.

12. Health Protection Agency (2006): Surveillance of Surgical Site Infection in England. London. Journal of hospital infection. 45 (Suppl 2):90-35.

13. Health Protection Agency (2012): Surveillance of Surgical Site Infection in England. London. Journal of hospital infection. 65 (Suppl 2):16570.

14. Jan M., \& Foreen R., (2015): Surgical Site Infection P: Nursing Management.Wolters Kluwer.Lippincott Nursing Center. P 16-20.

15. Kabir H., (2010): Nurses Knowledge and Practice regarding Prevention of Surgical Site Infection in Bangladesh. Master thesis. Prince of Songkla University, Pp. 53-61

16. Labrague L., Atrteche D., Yboba B., \& Pacolor N., (2012): Operating Room Nurses Knowledge and Practice of Sterile Technique. Journal Nurse Care Volume 1(4), Pp. 1-5

17. Khalifa H., (2011): Assessment of nurses' performance regarding reducing or preventing of nosocomial infection for patients with cancer. Master degree in medical- surgical nursing, faculty of nursing, Assuit University, 80-95.

18. Niemeyer L., Hosokawa P., \& Itani K., (2007): Multivariable predictors of postoperative surgical site infection after general and vascular surgery: results from the patient safety in surgery study. Journal of the American college of surgeons. 204:1178-87

19. Patricia A.., \& Anne G., (2009): Fundamentals of Nursing, $5^{\text {th }}$ ed. Mosby, London, Sydney: 835 879.

20. Scott R., (2009): The Direct Medical Costs of Healthcare Associated Infections in US. Hospital and the Benefits of Prevention. Atlanta: Centers for Disease Control and Prevention

21. Soliman S., (2007): Assessment of Nurses Knowledge and Attitude toward Infection Standard Precautions in Primary Health Care Setting, Bulletin of High Institute of public Health; 37(1): 189-196

22. Vanessa N., (2009): Wound infectionsemedicine dermatology, definition of surgical site infection, Infect Cont Hosp Ep USA 18,659668 